\title{
Prevalence of Malocclusion in the Southern Region of Jeddah, KSA, and Its Impact on Quality of Life - A Cross-Sectional Study
}

\author{
Ahmed Habiballah Marghalani ${ }^{1}$, Abdulrhman Safwan Al-Mahmoud ${ }^{2}$, Dania M. Nazir Chaar ${ }^{3}$ \\ Ghada Mohamed Rabie ${ }^{4}$, Nada Ibrahim Alzurqi ${ }^{5}$, Fatima Al Zahra ${ }^{6}$
}

1,2, 3, 4, 5, 6 Department of Preventive Dental Science, Ibn-Sina National College for Medical Studies, Jeddah, Saudi Arabia.

\section{ABSTRACT}

\section{BACKGROUND}

Dental malocclusion not only affects the functional abilities and aesthetic features of an individual, but also affects the psychological status of an individual. The study aims to address the necessity of orthodontic treatment using the Orthodontic Treatment Needs Index (IOTN) and its influence on the individual's quality of life using the Oral Health Impact Profile (OHIP-14) Index on adults undergoing dental treatment in Ibn Sina National college, dental clinics.

\section{METHODS}

401 adult subjects undergoing treatment at Ibn Sina National College, dental clinics were selected randomly for the study. The subjects were examined by 5 calibrated dentists. For each patient, two indices, IOTN and OHIP-14 were recorded. Each subject's relationship of teeth was recorded on a dental chair equipped with natural and dental light. Angle's molar and canine classification, overjet, overbite were recorded to reach an IOTN score. The influence on quality of life was determined using the OHIP-14 index by asking questions regarding functional limitation, physical pain and disability, and social discomfort.

\section{RESULTS}

Out of 401 participants, $57.4 \%$ were females and $42.6 \%$ were males. The mean age of the participants was found to be $29.94 \pm 10.75$ years. The functional limitations for pronouncing words among the participants were statistically significant. Physical pain and disability, psychological discomfort and disability, as well as social disability domains showed a statistically significant association, whereas the relationship of handicapped with IOTN grades were not statically significant $(\mathrm{P}<0.001)$.

\section{CONCLUSIONS}

Prevention is better than cure. Masticatory difficulty has been noted among class III, class II, and class I malocclusions respectively in descending order with class III facing the most difficulty. It has been noted that malocclusion in different scales affected individual's ability to process and break down food. Early diagnosis and treatment are important.

\section{KEY WORDS}

Malocclusion, OHIP, IOTN, Orthodontic Treatment, Quality of Life.
Corresponding Author: Dr. Ahmed Marghalani, Department of Preventive Dental Science, Ibn-Sina National College for Medical Studies, Jeddah, Saudi Arabia.

E-mail:ahmed.marghalani@ibnsina.edu.sa

\section{DOI: $10.14260 / j e m d s / 2021 / 165$}

How to Cite This Article:

Marghalani AH, Al-Mahmoud AS, Chaar $D M N$, et al. Prevalence of malocclusion in the Southern region of Jeddah, KSA, and its impact on quality of life - a cross-sectional study. J Evolution Med Dent Sci 2021;10(11):768-772, DOI: 10.14260/jemds/2021/165

Submission 06-10-2020,

Peer Review 24-01-2021,

Acceptance 30-01-2021,

Published 15-03-2021.

Copyright (c) 2021 Ahmed Habiballah Marghalani et al. This is an open access article distributed under Creative Commons Attribution License [Attribution 4.0 International (CC BY 4.0)] 


\section{BACKGROUND}

Due to recent advances in the field of orthodontics, concerns from the general society regarding aesthetics, and general form and appearance, the demand for orthodontic therapy has significantly increased. Patients usually desire orthodontic treatment to improve function and aesthetics, rather than the purpose of treating oral "disease. 1 "

The main reason for orthodontic treatment is to enhance patient's aesthetics. However, the need for orthodontic treatment is influenced by the patient's perception and the orthodontist clinical examination, this will increase awareness of the patient's "situation. 2,3 " Two indices were used to evaluate the degree of treatment needed: IOTN and the OHIP.

Over the past years, few studies have been done in the Western region of Saudi Arabia to classify the degree of malocclusion on young individuals and the orthodontic

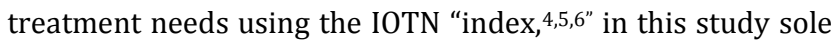
focus was on part of the Western region localised to Southern area of Jeddah, KSA.

Malocclusion can have some negative psychological impact on the individual. It can be devastating and dramatically affects quality of life of an individual, research has shown a significant improvement in quality of life post orthodontic "treatment.7,8" Malocclusion not only affects the aesthetic and functional abilities of an individual; psychological aspect of the individual is affected as well influences the self-esteem, socialising and inter-personal relationship of the individual; so, the oral health related quality of life will be affected. Hence, this study was planned to analyse the effects of malocclusion on an individual well-being.

\section{METHODS}

This study is a cross-sectional evaluation of adult patients undergoing treatment at Ibn Sina National College in Jeddah, Saudi Arabia. Research data collection initiated after obtaining approval from institutional ethics committee, Ibn Sina National College for Medical Studies (IEC Reference Number: H-02-22122019). Subjects were examined by 5 calibrated dentists after signing an informed consent. A calculated sample size of 401 adult subjects undergoing treatment were selected randomly and for each patient 2 indices were recorded: Orthodontic-Treatment Need Index and Oral Health Impact Profile-14.

Patients with the following conditions were excluded

1. Severe dento-facial anomalies

2. Cleft lip and palate

3. Past orthodontic treatment

4. Those requiring orthognathic surgeries

5. Serious medical conditions.

Patients with the following conditions were included

1. No previous history of orthodontic therapy

2. Subjects who were 14 years old and above, with fully erupted permanent second molars

3. Medically fit patients.

Written informed consent was obtained from each subject, armamentarium used were basic diagnostic kit, dental chair equipped with natural and dental light.

\section{Malocclusion Assessments}

It was done by using the Orthodontic Treatment Need Index. IOTN is a rating system that is aimed to determine the impact of malocclusion and severity on dental health. It gives a priority for the individuals who need treatment the most. ${ }^{9}$ And it was done with the use of natural light, dental light and diagnostic kits.

Severity of each participants was recorded through components of IOTN which are: Grade 1: implies no treatment need, Grade 2: implies mild or little need, Grade 3: implies moderate or borderline treatment need, and Grades 4 \& 5: implies severe or extreme treatment need.

The questionnaires using OHIP-14 covered the seven domains of oral health: functional limitation, physical pain, psychological discomfort, physical disability, psychological disability, social disability, and handicap. Appendix B shows the OHIP questionnaire. ${ }^{1}$

\section{Statistical Analysis}

The data obtained was transferred to the Microsoft Excel and subjected to statistical comparison. Data processing was done through statistical analysis software, Statistical Package for the Social Science.

SPSS version 23 (IBM corps, Armonk, NY, USA). Descriptive analysis of the data was performed. Pearson's chi-square test was performed to correlate in the IOTN and the OHIP-14.

\section{RESULTS}

Our study consisted of a total of 401 participants, of whom $57.4 \%$ were females and $42.6 \%$ were males. The mean age of the participants was found to be $29.94 \pm 10.75$ years (Table 1 ).

When we assessed the distribution of IOTN grades, it was found that $39.7 \%$ had grade $1,36.7 \%$ had grade $2,16.7 \%$ had grade 3, $5.7 \%$ had grade 4 and $1.2 \%$ had grade 5 (Table 2). When the relationship of the gender with different grades of IOTN was analysed, there was no statistically significant association observed (X2 $=1.613, \mathrm{P}>0.05$ ) (Table 2)

\begin{tabular}{|cccccc|}
\hline & N & Mean & Std. Deviation & Minimum & Maximum \\
Female & 230 & 29.83 & 10.68 & 14.00 & 66.00 \\
Male & 171 & 30.07 & 10.89 & 6.00 & 75.00 \\
Total & 401 & 29.94 & 10.75 & 6.00 & 75.00 \\
\hline \multicolumn{5}{c}{ Table 1. Mean Age of the Participants } \\
\hline
\end{tabular}

The evaluation of functional limitations among the participants showed that $25.56 \%$ had reported the same. It was found that grade 3,4 and 5 had comparatively more troubles in pronouncing some words than grade 1 and 2 which showed a statistically significant relationship $(\mathrm{X} 2=21.94, \mathrm{P}<$ 0.001) (Table 3).

When we assessed the domain 'physical pain', it was found that $28.5 \%$ had reported having some form of physical pain. Except for participants with grade 1 all other grades of IOTN in our study had reported aching in the mouth $\left(\mathrm{X}^{2}=18.46, \mathrm{P}<\right.$ $0.05)$ and also felt some pain while having food ( $\mathrm{X} 2=35.2, \mathrm{P}<$ $0.001)$, which showed a statistically significant association. (Table 3) 


\begin{tabular}{|c|c|c|c|c|c|c|c|c|c|}
\hline & & \multicolumn{5}{|c|}{ IOTN Grading Index } & \multirow{2}{*}{ Total } & \multirow{2}{*}{$\begin{array}{l}\text { Pearson's } \\
\text { Chi-Square }\end{array}$} & \multirow{2}{*}{ P-Value } \\
\hline & & Grade 1 & Grade 2 & Grade 3 & Grade 4 & Grade 5 & & & \\
\hline & Female & 95 (41.3\%) & 85 (37.0\%) & $36(15.7 \%)$ & 11 (4.8 \%) & $3(1.3 \%)$ & $230(100 \%)$ & \multirow{2}{*}{1.613} & \multirow{2}{*}{0.806} \\
\hline Gender & Male & $64(37.4 \%)$ & $62(36.3 \%)$ & $31(18.1 \%)$ & $12(7.0 \%)$ & $2(1.2 \%)$ & $171(100 \%)$ & & \\
\hline \multicolumn{10}{|c|}{ Table 2. Distribution of IOTN Grades Based on Gender } \\
\hline
\end{tabular}

\begin{tabular}{|c|c|c|c|c|c|c|c|c|c|c|c|}
\hline & & & & & IOTN Gr & rading Index & & & & & \\
\hline & & & & Grade 1 & Grade 2 & Grade 3 & Grade 4 & Grade 5 & Total & $x^{2}$ & PValue \\
\hline కే & Have you had any trou & ubles & Yes & $\begin{array}{c}38 \\
35.5 \%\end{array}$ & $\begin{array}{c}28 \\
26.2 \%\end{array}$ & $\begin{array}{c}27 \\
25.2 \%\end{array}$ & $\begin{array}{c}10 \\
9.3 \%\end{array}$ & $\begin{array}{c}4 \\
3.7 \%\end{array}$ & $107100 \%$ & & \\
\hline$\stackrel{\widetilde{\pi}}{\Xi}$ & pronouncing any wo & & No & 121 & 119 & 40 & 13 & 1 & 294 & 21.94 & $<0.001$ \\
\hline స్ & $x_{-1}$ & & & $\begin{array}{c}41.2 \% \\
33\end{array}$ & $\begin{array}{c}40.5 \% \\
39\end{array}$ & $\begin{array}{c}13.6 \% \\
14\end{array}$ & $\begin{array}{c}4.4 \% \\
9\end{array}$ & $\begin{array}{c}0.3 \% \\
3\end{array}$ & $\begin{array}{l}100 \% \\
98\end{array}$ & & \\
\hline : & Have you felt that your s & ense of & Yes & $33.7 \%$ & $39.8 \%$ & $14.3 \%$ & $9.2 \%$ & $3.1 \%$ & $100 \%$ & 8.08 & 0.089 \\
\hline & taste has worsenec & d? & & 126 & 108 & 53 & 14 & 2 & 303 & 8.08 & 0.089 \\
\hline & & & No & $41.6 \%$ & $35.6 \%$ & $17.5 \%$ & $4.6 \%$ & $0.7 \%$ & $100 \%$ & & \\
\hline & & & & 30 & 45 & 24 & 10 & 4 & 113 & & \\
\hline & Have you had any painfu & 1 aching & Yes & $26.5 \%$ & $39.8 \%$ & $21.2 \%$ & $8.8 \%$ & $3.5 \%$ & $100 \%$ & & 0.001 \\
\hline & in your mouth? & & & 129 & 102 & 43 & 13 & 1 & 288 & 18.46 & 0.001 \\
\hline चे & & & NO & $44.8 \%$ & $35.4 \%$ & $14.9 \%$ & $4.5 \%$ & $0.3 \%$ & $100 \%$ & & \\
\hline$\frac{u}{n}$ & & & & 28 & 44 & 25 & 17 & 2 & 116 & & \\
\hline$\vec{e}$ & Have you found it uncom & fortable & Yes & $24.1 \%$ & $37.9 \%$ & $21.6 \%$ & $14.7 \%$ & $1.7 \%$ & $100 \%$ & & \\
\hline & eating any food? & & & 131 & 103 & 42 & 6 & 3 & 285 & 35.20 & $<0.001$ \\
\hline & & & No & $46.0 \%$ & $36.1 \%$ & $14.7 \%$ & $2.1 \%$ & $1.1 \%$ & $100 \%$ & & \\
\hline & & & & 21 & 42 & 30 & 12 & 4 & 109 & & \\
\hline & Have you been self-con & scious & Yes & $19.3 \%$ & $38.5 \%$ & $27.5 \%$ & $11.0 \%$ & $3.7 \%$ & $100 \%$ & 40.16 & $<0.001$ \\
\hline & about your oral stat & & & 138 & 105 & 37 & 11 & 1 & 292 & 40.16 & $<0.001$ \\
\hline Psychological & & & No & $47.3 \%$ & $36.0 \%$ & $12.7 \%$ & $3.8 \%$ & $0.3 \%$ & $100 \%$ & & \\
\hline discomfort & & & & 26 & 48 & 14 & 11 & 2 & 101 & & \\
\hline & Are you tense regarding $p$ & roblems & Yes & $25.7 \%$ & $47.5 \%$ & $13.9 \%$ & $10.9 \%$ & $2.0 \%$ & $100 \%$ & & \\
\hline & in your occlusion & & & 133 & 99 & 53 & 12 & 3 & 300 & 18.428 & 0.001 \\
\hline & & & No & $44.3 \%$ & $33.0 \%$ & $17.7 \%$ & $4.0 \%$ & $1.0 \%$ & $100 \%$ & & \\
\hline$T$ & ble 3. Responses of Par & $\overline{t i} \mathbf{i}$ & s Regardin & Functional D & isability, Phys & sical Pain, anc & Id Psychologi & ical Disco & mfort Base & IOTN & des \\
\hline & & & & Level & of significance & $\mathrm{e} P<0.05$ & & & & & \\
\hline & & & & & TN Grading In & ndex & & & & $\mathrm{X}^{2}$ & P Value \\
\hline & & & Grade 1 & Grade 2 & Grade 3 & Grade 4 & Grade 5 & & Total & $x^{2}$ & PValue \\
\hline & & & 25 & 37 & 18 & 5 & 4 & & 89 & & \\
\hline & Has your diet been & Yes & $28.1 \%$ & $41.6 \%$ & $20.2 \%$ & $5.6 \%$ & $4.5 \%$ & & $100 \%$ & & \\
\hline 言 & unsatisfactory? & & 134 & 110 & 49 & 18 & 1 & & 312 & 15.134 & 0.004 \\
\hline$\frac{\widetilde{m}}{7}$ & & No & $42.9 \%$ & $35.3 \%$ & $15.7 \%$ & $5.8 \%$ & $0.3 \%$ & & $100 \%$ & & \\
\hline तु & & & 26 & 39 & 18 & 13 & 3 & & 99 & & \\
\hline$\frac{\omega}{n}$ & $\begin{array}{l}\text { Did you interrupt a } \\
\text { meal before due to yur }\end{array}$ & Yes & $26.3 \%$ & $39.4 \%$ & $18.2 \%$ & $13.1 \%$ & $3.0 \%$ & & $100 \%$ & & $<0.001$ \\
\hline & $\begin{array}{l}\text { meal betore due to your } \\
\text { condition? }\end{array}$ & No & 133 & 108 & 49 & 10 & 2 & & 302 & 22.270 & $<0.001$ \\
\hline & & No & $44.0 \%$ & $35.8 \%$ & $16.2 \%$ & $3.3 \%$ & $0.7 \%$ & & $100 \%$ & & \\
\hline & & & 27 & 46 & 27 & 13 & 4 & & 117 & & \\
\hline & Have you found it & Yes & $23.1 \%$ & $39.3 \%$ & $23.1 \%$ & $11.1 \%$ & $3.4 \%$ & & $100 \%$ & 30346 & $<0001$ \\
\hline & difficult to relax? & No & 132 & 101 & 40 & 10 & 1 & & 284 & 30.346 & $<0.001$ \\
\hline & & NO & $46.5 \%$ & $35.6 \%$ & $14.1 \%$ & $3.5 \%$ & $0.4 \%$ & & $100 \%$ & & \\
\hline disability & Are you embarrassed & Yes & 27 & 47 & 21 & 13 & 3 & & 111 & & \\
\hline & $\begin{array}{l}\text { Are } \\
\text { even a bit with your }\end{array}$ & res & $24.3 \%$ & $42.3 \%$ & $18.9 \%$ & $11.7 \%$ & $2.7 \%$ & & $100 \%$ & 23.060 & $<0.001$ \\
\hline & $\begin{array}{l}\text { even a bit with your } \\
\text { arat status? }\end{array}$ & & 132 & 100 & 46 & 10 & 2 & & 290 & 23.060 & $<0.001$ \\
\hline & oral status? & No & $45.5 \%$ & $34.5 \%$ & $15.9 \%$ & $3.4 \%$ & $0.7 \%$ & & $100 \%$ & & \\
\hline
\end{tabular}

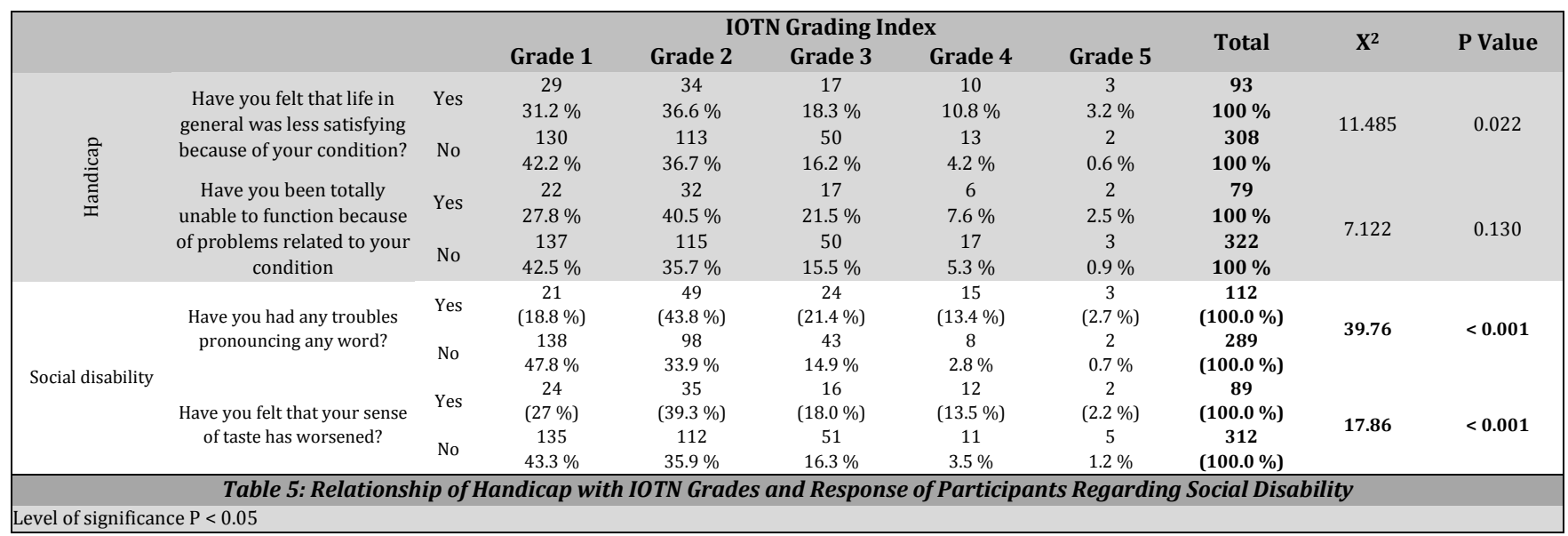


It was found that $26.18 \%$ had some kind of psychological discomfort among our participants. $86.79 \%(n=138)$ of participants who had IOTN as grade 1 were not self-conscious about their oral status and also $83.6 \%$ of grade $1(n=44.3 \%)$ were not tensed regarding their occlusion compared to other grades of IOTN that showed statistically significant association (Table 3)

When the responses related to the domain 'physical disability' was recorded it was found that 89 (22.19\%) participants had unsatisfactory diet and 99 (24.68\%) participants had reported that they had an interrupted meal due to their condition. Participants with grade 1 were comparatively having no physical disability compared to those with higher grades of IOTN that showed statistically significant association. (Table 4).

The assessment of psychological disability among participants showed that those who had grade 1 IOTN showed comparatively little disability to other higher grades $(\mathrm{P}<$ 0.001) (Table 4).

When we evaluated the responses regarding being handicapped, it was found that $21.44 \%$ of the participants were handicapped in some ways. When the relationship of IOTN and handicapped was assessed it was observed that people with grades 1 and 2 had reported comparatively satisfied life than those with higher grades of IOTN. (Table 5)

When the domain 'social disability' was assessed, it was found that participants with grade 1 had comparatively less problems related to social disability, whereas grade 2, 3, 4, 5 individuals reported more issues with this domain, and this was statistically significant. $(\mathrm{P}<0.001)$ (Table 5).

\section{DISCUSSION}

The perception of beauty has transformed among the users of social media, which led to lack of acceptance of malocclusion and admiration of the Hollywood smile. According to OHIP questionnaire, moderate to severe malocclusion that was untreated showed a negative reflection on quality of life.

In our study, the mean age was $29.94 \pm 10.75$ years. "Choi et al.10" evaluated 472 patients aged 21.1 years who visited their department in Seoul, Korea, which had a similar age group as our study.

Choi et al. concluded that severe malocclusion was more in patients visiting the dental hospitals compared to the private clinics. They also reported that lower quality of life and masticatory efficiency was correlated to more severe malocclusion in older patients. Jamilian et "al11" reported that moderate to severe malocclusion had less negative impact after orthodontic treatment, whereas our study has excluded pre-orthodontically treated patients.

In our study, we evaluated the severity of malocclusion between genders and found that the relationship between the gender and the grade of IOTN shows that there is no remarkable association.

Barakat et "al12" referred that quality of life was not overall affected as long as functional ability and aesthetics was not "compromised.13" But in our study we viewed the functional disability participants with grade 3,4 and 5 showed troubles in pronouncing words (Table 3). And for the physical pain all grades reported physical pain in their mouth except grade 1 and also pain while chewing food. (Table 3) This is similar to the findings of previous studies.

Our study estimated in regard to psychological discomfort all the participant were self-conscious about their oral status except those who were classified as grade 1 and those who complained of being tensed regarding problems with their occlusion varied from grade 2, 4 and 5 (Table 3 ).

Our study calculated the physical disability participants with grade 2, 3 and 5. They have been unsatisfied about their diets, all the participants reported that they interrupted their meal due to their condition except grade 1 (Table 4).

Based on psychological disability in our study, participants who had disability to relax and were embarrassed of their oral status were from grade 2 to 5 (Table 4).

In our study, we assessed the relationship of handicap with IOTN people with grade 2, 3 and 5. They felt that their life in general was less satisfying due to their condition and people with grade 2, 3, 5 said that they were unable to function because of the problems related to their conditions except grade 1 (Table 5). The domain handicap does not refer to the functional disability but to the negative impact on social life and self-perceptions.

To determine the social disability in our study, participants with grade 2, 3, 4, 5 were compared to those of grade 1 (Table 5). This highlights the social impact on quality of life of malocclusions individuals.

Orthodontists should fulfil the need of their patients for orthodontic treatment, not only for functioning, but also to escalate their self-esteem and aesthetics, especially the patients in Southern Jeddah are not aware of the importance of orthodontic treatment and mostly cannot afford it. When these needs are not met it leads to dissatisfaction and negatively affect their social life, This study focuses of the treatment needs in the area and its impact on quality of life and how such matter affects individuals social status among the community.

Data obtained from this research may be used in future researches to calculate manpower required in the area to perform required treatments.

\section{CONCLUSIONS}

Malocclusions were almost similar in both genders although the physiological impact on quality of life was more evident in female patients. Masticatory difficulty has been noted among class III, class II, and class I malocclusions respectively in descending order with class III facing the most difficulty. It has been noted that malocclusion in different scales affected individual's ability to process and break down "food. 14" Early diagnosis and treatment must be implemented to avoid disappointment of any sort to individual's life in the future; the matter of urgent need to educate parents with school age children regarding malocclusion and the importance of early treatment must be a priority in public health programs to prevent future psychological distress among individuals of the siciety. According to results, more severe malocclusions demonstrated lower quality of life and masticatory efficiency. 
Data sharing statement provided by the authors is available with the full text of this article at jemds.com.

Financial or other competing interests: None.

Disclosure forms provided by the authors are available with the full text of this article at jemds.com.

\section{REFERENCES}

[1] Slade GD. Assessment of oral health-related quality of life. In: Inglehart MR, Bagramian RA, eds. Oral health-related quality of life. Chicago: Quintessence 2002:29-46.

[2] Al-Jobair AM, Baidas LF, Al-Hamid AA, et al. Orthodontic treatment need among young Saudis attending public versus private dental practices in Riyadh. Clin Cosmet Investig Dent 2016;8:121-9.

[3] Janošević $P$, Stošić $M$, Janošević $M$, et al. Index of orthodontic treatment need in children from the Niš region. Vojnosanit Pregl 2015;72(1):12-5.

[4] Masood Y, Masood M, Zainul N, et al. Impact of malocclusion on oral health related quality of life in young people. Health Qual Life Outcomes 2013;11(1):25.

[5] Hassan AH. Orthodontic treatment needs in the western region of Saudi Arabia: a research report. Head Face Med 2006;2:2.

[6] Baeshen $H$. The prevalence of major types of occlusal anomalies among Saudi middle school students. J Contemp Dent Pract 2017;18(2):142-6.

[7] van Wezel NA, Bos A, Prahl C. Expectations of treatment and satisfaction with dentofacial appearance in patients applying for orthodontic treatment. Am J Orthod Dentofacial Orthop 2015;147(6):698-703.

[8] Richards MR, Fields HW, Beck FM, et al. Contribution of malocclusion and female facial attractiveness to smile esthetics evaluated by eye tracking. Am J Orthod Dentofacial Orthop 2015;147(4):472-82.

[9] Brook PH, Shaw WC. The development of an index for orthodontic treatment priority. Eur J Orthod 1989;11(3):309-20.

[10] Fernandes MJ, Ruta DA, Ogden GR, et al. Assessing oral health-related quality of life in general dental practice in Scotland: validation of the OHIP-14. Community Dent Oral Epidemiol 2006;34(1):53-62.

[11] Choi SH, Kim JS, Cha JY, et al. Effect of malocclusion severity on oral health-related quality of life and food intake ability in a Korean population. Am J Orthod Dentofacial Orthop 2016;149(3):384-90.

[12] Barakat LF, Ucheonye IJ. Oral health impact profile (OHIP14) and its association with dental treatment needs of adolescents in a rural Nigerian community. Brazilian Journal of Oral Sciences 2016;15(3):215-20.

[13] Hassan AH, Hassan MH, Linjawi AI. Association of orthodontic treatment needs and oral health-related quality of life in Saudi children seeking orthodontic treatment. Patient Prefer Adherence 2014;8:1571-9.

[14] English JD, Buschang PH, Throckmorton GS. Does malocclusion affect masticatory performance? Angle Orthod 2002;72(1):21-7. 